\title{
Affective and Cardiovascular Responding to Unpleasant Events From Adolescence to Old Age: Complexity of Events Matters
}

\author{
Cornelia Wrzus and Viktor Müller \\ Max Planck Institute for Human Development
}

\author{
Gert G. Wagner \\ German Institute for Economic Research and Max Planck \\ Institute for Human Development
}

\author{
Ulman Lindenberger and Michaela Riediger \\ Max Planck Institute for Human Development
}

\begin{abstract}
Two studies investigated the overpowering hypothesis as a possible explanation for the currently inconclusive empirical picture on age differences in affective responding to unpleasant events. The overpowering hypothesis predicts that age differences in affective responding are particularly evident in highly resource-demanding situations that overtax older adults' capacities. In Study 1, we used a mobile phone-based experience-sampling technology in 378 participants $14-86$ years of age. Participants reported their momentary negative affect and occurrences of unpleasant events on average 54 times over 3 weeks. In Study 2, a subsample of 92 participants wore an ambulatory psycho-physiological monitoring system for $24 \mathrm{hr}$ while pursuing their daily routines and additionally completed an average of 7 mobile phone-based experience-sampling reports. Affective responding was analyzed by comparing, within persons, affective states in situations without and with preceding unpleasant events. Results support the overpowering hypothesis: When dealing with complex unpleasant events that affected multiple life domains, both psychological (Study 1) and cardiovascular (Study 2) responding to unpleasant events were more pronounced the older the participants were. When dealing with circumscribed unpleasant events, however, no age differences in psychological responding were observed (Study 1), and cardiovascular responding was even less pronounced the older the participants were (Study 2). These findings are consistent with the notion of preserved affect regulation throughout adulthood, as long as the resource demands exerted by an event do not overtax the individual's capacities. We conclude that the overpowering hypothesis can bridge previously opposing positions regarding age differences in affective responding.
\end{abstract}

Keywords: affective responding, cardiovascular activity, experience sampling, lifespan development, emotion regulation

Every once in a while, we encounter unpleasant events in our life: We run late because our car breaks down, we are disappointed by someone who has not kept their word, or we fail to meet a goal

This article was published Online First April 30, 2012

Cornelia Wrzus and Viktor Müller, Max Planck Institute for Human Development, Berlin, Germany; Gert G. Wagner, German Institute for Economic Research, Berlin, Germany, and Max Planck Institute for $\mathrm{Hu}-$ man Development; Ulman Lindenberger and Michaela Riediger, Max Planck Institute for Human Development.

This research was funded by the German Federal Ministry for Education and Research (Grants 01UW0706 and MPI001) and by the Max Planck Society. We thank Bit-side $\mathrm{GmbH}$ for the development of the mobilephone experience sampling software; Infratest Sozialforschung-and especially Andreas Stocker-for the data collection in Study 1; as well as Elisabeth Blanke, Anja Böhnke, Moritz Eberhardt, Dulce Erdt, Luara Ferreira dos Santos, Benjamin Frettlöh, Jörg-Tobias Hof, Teresa Holtfreter, Giorgi Kobakhidze, Kathrin Klipker, Maria Lößner, Alf Mante, Doreen Müller, Annette Rentz-Lühning, Stefan Schauber, and Susanne Wilhem for helping to conduct the study. We are grateful to Julia Delius and Grace O'Malley for editorial assistance.

Correspondence concerning this article should be addressed to Cornelia Wrzus, Max Planck Institute for Human Development, Lentzeallee 94, 14195 Berlin, Germany. E-mail: wrzus@mpib-berlin.mpg.de that we consider as important for our future. Such unpleasant events do not leave us unaffected. They may elicit changes in our feelings, behaviors, or even physiological states. Yet, people vary in the extent of their affective responding to unpleasant events. Whereas a given event may elicit slight annoyance in one person, it may lead to seething rage in another.

Several researchers have argued that people's age may be among the factors that are related to individual differences in affective responding (Birditt, Fingerman, \& Almeida, 2005; Mroczek \& Almeida, 2004; Neupert, Almeida, \& Charles, 2007; Sliwinski, Almeida, Smyth, \& Stawski, 2009). To date, however, both theory and empirical evidence regarding this idea have been controversial. Here, we propose and test the overpowering hypothesis as a possible explanation for the dissensus. Thus, we might help to clarify the picture of age-related differences in people's responding to emotional events, focusing on the age range from adolescence to old age. As elaborated in more detail below, the overpowering hypothesis maintains that age differences in affective responding depend on the demand characteristics of the unpleasant event. We predict stronger affective responses among older adults compared to younger individuals when encountering complex events, that is, events with implications for multiple life domains. In contrast, 
we predict no age differences or even less affective responding among older adults to circumscribed events that affect single life domains only.

In this article, we report two studies that investigated the overpowering hypothesis in terms of both psychological and physiological responding to unpleasant events. To assess these facets of affective responses as they naturally occur in people's daily lives, we combined mobile phone-based experiencesampling and ambulatory psycho-physiological monitoring. Unlike previous studies that often relied on end-of-day reports (e.g., Mroczek \& Almeida, 2004; Sliwinski et al., 2009), we repeatedly assessed affective processes at the moment of their occurrence in the participants' natural life contexts. This approach allows the assessment of affective responding in close temporal proximity to an unpleasant event and, thus, minimizes possible effects of age-related differences in remembering or reporting events and experiences (Craik, 1999), or in recovering from events due to regulatory processes, such as reappraisal of the event or of one's affective experiences (Levine \& Bluck, 1997).

\section{Theoretical Perspectives on Adult Age Differences in Affective Responding}

Reactions to emotional events occur on multiple levels: They can be reflected in changes in people's emotional states (e.g., from feeling relaxed to feeling angry), changes in their outward behaviors (e.g., from smiling to frowning), as well as in changes in their autonomic activation (e.g., from lower to higher heart rate). We refer to these changes as affective responding to delineate them from the typically more narrowly defined phenomena of stress reaction and coping (Gross \& Thompson, 2007; Lazarus, 1999), which have mainly been studied in relation to critical life events and longer-term adjustment (Holmes \& Rahe, 1967; Lazarus, 1999, 2000). In this article, we are interested in people's reactions to the unpleasant events they encounter in their daily lives, which typically have more short-term effects on affective functioning. We suppose that basic assumptions of prominent stress theories also apply to such minor events and that combining the perspectives from stress research and from developmental investigations additionally enhances the understanding of individual differences in affective responding. That is, we proceed from the idea akin to the proposition in Lazarus and Folkman's (1984) stress model that person and situation characteristics may influence responses to unpleasant or stressful events. Extending this idea, we further propose that a person's age is an important person characteristic that moderates specific situational effects.

Contemporary theoretical positions on adult changes in the ability to regulate emotional states give rise to seemingly opposing expectations regarding adult age differences in affective responding. One position, maintained by dynamic integration theory (Labouvie-Vief, 2003, 2008; Labouvie-Vief, Jain, Diehl, \& Fang, 2007), suggests that older adults are less effective than younger individuals in regulating affective experiences because situational demands exceed their available cognitive capacities. This position relates to the idea that regulating affective responses is largely cognitively controlled and therefore consumes cognitive capacity (Ochsner \& Gross, 2004; Richards \&
Gross, 1999). As cognitive resources, and among them executive control abilities, decline with age (Ferrer-Caja, Crawford, \& Bryan, 2002; Verhaeghen \& Salthouse, 1997), the capacity to regulate emotions effectively in the face of adversity should be reduced. This should result in more pronounced responding to unpleasant events.

A different position derives from socioemotional selectivity theory (Carstensen, 1992; Carstensen, Pasupathi, Mayr, \& Nesselroade, 2000), which postulates that shrinking horizons of time to live increase older adults' motivation to maximize their emotional well-being in the here and now. Older adults are thus expected to be increasingly motivated to influence their affective states toward experiencing less negative and more positive emotionality; and as a result of life experience, they are expected to be increasingly proficient at doing so (e.g., Charles \& Carstensen, 2010). Better emotional well-being of older adults compared to younger individuals is seen as resulting both from volitional (Fitzsimons \& Bargh, 2004; Gross \& Thompson, 2007) and automatic (Williams, Bargh, Nocera, \& Gray, 2009) regulatory efforts. Although behavioral evidence supporting this claim is still scarce (Isaacowitz \& Blanchard-Fields, 2012; Larcom \& Isaacowitz, 2009), self-report studies show that older adults indeed view themselves as more in control of their affective experiences than younger adults (Carstensen \& Charles, 1998; Gross et al., 1997; Lawton, 2001; Lawton, Kleban, Rajagopal, \& Dean, 1992). This idea of enhanced emotion-regulation effectiveness throughout adulthood suggests that older adults, compared to younger adults, should be more in control of their responses and, hence, less responsive when confronted with unpleasant events.

In short, contemporary lifespan theories on affective functioning suggest opposing predictions regarding age-related differences in people's responding to unpleasant events. Interestingly, empirical evidence regarding adult age differences in both psychological and cardiovascular responding to emotion-eliciting events is similarly inconclusive, as summarized next.

\section{Mixed Evidence Regarding Age Differences in Psychological and Cardiovascular Responding to Unpleasant Events}

Relevant empirical investigations have mostly focused on age-related differences in either psychological or physiological responding to unpleasant experiences. Psychological responding is typically operationalized as changes in people's daily affective experiences, often as increased negative affect on days with unpleasant experiences relative to other days without occurrences of unpleasant events. Findings from these studies range from age-related decreases (e.g., Brose, Schmiedek, Lövden, \& Lindenberger, 2011; Charles \& Carstensen, 2008), to no age-related differences (Bäckman \& Molander, 1986; Stawski, Almeida, Sliwinski, \& Smyth, 2008), and age-related increases in affective responding to unpleasant events (Mroczek \& Almeida, 2004; Sliwinski et al., 2009). We propose that this divergence in findings might be associated with differences in the emotional events that the various studies investigated. Even analyses of the same data set, the National Study of Daily Experiences (NSDE; Mroczek \& Almeida, 2004), yielded different results depending on how unpleasant events were opera- 
tionalized: When responding to circumscribed unpleasant events (e.g., minor argument with spouse) or to whether or not an unpleasant event had occurred that day, an age-related decrease (Birditt et al., 2005) or no age differences (Neupert et al., 2007) in affective responding were found. However, when daily affective responding was predicted from the severity of the unpleasant event, studies reported age-related increases in responding (Mroczek \& Almeida, 2004; Sliwinski et al., 2009). In these studies, more severe unpleasant events often dealt with complex problems or situations.

Investigations of age differences in physiological responding to unpleasant events have mostly focused on changes in cardiovascular functioning, most typically in heart rate or systolic blood pressure in the laboratory. A recent meta-analysis of 31 experimental studies showed that heart rate increases less strongly and that systolic blood pressure increases more strongly with age in reaction to emotionally evocative tasks (Uchino, Birmingham, \& Berg, 2010). This divergence of findings is likely due to the different regulatory pathways involved. Heart rate is regulated by influences from both the sympathetic and the parasympathetic nervous system, whereas systolic blood pressure is mainly regulated by the sympathetic system and baroreceptors of the blood vessels (Burg \& Pickering, 2011). The sympathetic system increases energy supply, whereas the parasympathetic system exerts antagonistic effects by calming the organism and restoring homeostasis. Both heart rate and systolic blood pressure are measures not well suited for testing the conceptual considerations described above-that is, assumptions regarding people's regulatory efforts to remain in, or come back to, homeostasis or well-being. On a physiological level, such regulatory processes are best reflected in changes of parasympathetic activity, supplying inhibitory control on the heart (Berntson et al., 1997; Porges, Doussard-Roosevelt, \& Maiti, 1994).

In terms of cardiovascular functioning, parasympathetic influences are reflected, for example, in measures of heart rate variability (cf. Diamond \& Otter-Henderson, 2007; Malik et al., 1996). Heart rate variability results from an interaction between the cardiac and respiratory systems under parasympathetic control. During inhalation, parasympathetic control decreases somewhat, which leads to a slight increase in heart rate, while during exhalation, the pattern is reversed. The physiological function of heart rate variability is to maximize the efficiency of pulmonary gas exchange. Thus, in general, a certain level of variability in heart rate is characteristic of normal functioning. In stressful situations, heart rate variability decreases due to withdrawal of parasympathetic, and increase in sympathetic, influences, which result in more frequent, more regular, and less variable heart beats (Appelhans \& Luecken, 2006; Malik et al., 1996). This decline in heart rate variability serves the sympathetically mediated increase in energy supply that is necessary for responding to challenging events. Similar to the diverse pattern of findings regarding psychological responding, evidence regarding age differences in changes in heart rate variability in response to unpleasant events is also mixed and appears to vary depending on the complexity of the event: No age-related differences in change of heart rate variability were observed in response to a relatively circumscribed unpleasant situation of a reaction time task (Wood, Maraj, Lee, \& Reyes,
2002). In contrast, changes of heart rate variability were more pronounced with higher age in response to a complex unpleasant situation of preparing a speech to excuse a hypothetical shoplifting (Uchino, Holt-Lunstad, Bloor, \& Campo, 2005; Uchino, Uno, Holt-Lunstad, \& Flinders, 1999).

\section{Testing the Overpowering Hypothesis in the Present Research}

Proceeding from the observation that differences in findings from previous empirical studies might be associated with differences in the nature of the affect-eliciting event under investigation, we derived the overpowering hypothesis. The overpowering hypothesis offers a possible explanation for the inconclusive empirical picture and might bridge the apparently opposing conceptual stances as well. It proposes that age differences in affective responding are particularly evident in highly resource-demanding situations that overtax older adults' capacities. In such situations, we expected older adults to respond more strongly to unpleasant events than younger individuals because situational demands would exceed their available resources to successfully control affective responses. This hypothesis is informed by the proposition that age differences in cognitive performance are magnified when individuals approach their upper limits of performance (Baltes, 1987; Kliegl, Smith, \& Baltes, 1989; Lindenberger \& Baltes, 1995; for empirical evidence supporting this proposition, see, e.g., Baltes \& Kliegl, 1992; Brehmer, Li, Müller, von Oertzen, \& Lindenberger, 2007). When resource demands are low, however, we predicted no age differences or even an age-related decrease in affective responding to negative experiences, due to, for example, age-related increases in the motivation to experience pleasant affective states (Riediger, Schmiedek, Wagner, \& Lindenberger, 2009). Unpleasant events that affect multiple life domains are more complex to deal with than events with more circumscribed effects. In our research, we therefore used the number of life domains affected by a negative event as a proxy for the complexity of resource requirements imposed by the experience.

To account for the multi-dimensionality of affective responses, we conducted two studies that investigated the overpowering hypothesis in terms of both psychological and physiological responding to unpleasant events. In terms of psychological responding, we focus on changes in negative affect because negative affect has reliably been shown to increase in unpleasant situations (Mroczek \& Almeida, 2004; Steptoe, Moses, \& Edwards, 1990). In line with circumplex models of emotional experience (Russell, 1980; Watson \& Tellegen, 1985), we distinguish high-arousing negative affect (e.g., angry) from low-arousing negative affect (e.g., disappointed). We expect that the age-related increase in affective responding to complex unpleasant events predicted by the overpowering hypothesis should be most evident for high-arousing (as opposed to low-arousing) negative affect because older adults have been proposed to have increasing difficulties in dealing with emotional arousal (Charles, 2010) and to find arousing stimuli increasingly aversive (Keil \& Freund, 2009). With respect to physiological responding, we focus on heart rate variability as an indicator of the withdrawal of parasym- 
pathetic (calming) influences on the cardiovascular system in the face of adversity (Appelhans \& Luecken, 2006; Berntson et al., 1997; Malik et al., 1996).

Methodologically, we aimed at recruiting participants who are heterogeneous with respect to age, education, and gender to maximize the generalizability of our findings. Furthermore, to maximize the ecological validity of our assessments, we sought to measure psychological and physiological reactions to unpleasant events as they naturally occur in people's daily lives. We employed ecological momentary assessment technologies in two studies of individuals ranging in age from adolescence to old age to realize these aims. In Study 1, we used a mobile phone-based experience-sampling technology to obtain an average of 54 reports of momentary negative affect and occurrences of unpleasant events over the course of 3 weeks. Six assessments per day were scheduled throughout several days within a period of at least 3 weeks (see Method section for details) to achieve a balance between measuring densely per day and yet covering a larger, and thus more representative, time span. In Study 2, we combined experience sampling with 24-hr ambulatory assessment of cardiac and physical activity in daily life.

\section{Study 1-Age Differences in Psychological Responding to Unpleasant Events in Daily Life}

The aim of Study 1 was to investigate the overpowering hypothesis with respect to age differences in psychological responding to unpleasant events in everyday life. We predicted that everyday unpleasant events would be accompanied by relatively more intense high- and low-arousing negative affect compared to situations without unpleasant events. We expected these increases in negative affect to be more pronounced for complex unpleasant events that affected multiple life domains than for circumscribed events whose effects are restricted to one life domain. We further predicted that people's responding to complex, but not to circumscribed, negative events would be more pronounced with higher age, especially with respect to high-arousing negative affect.

\section{Method}

Participants. The fieldwork agency TNS Infratest Sozialforschung recruited 378 participants in three urban areas of Germany (Munich, Berlin, Duesseldorf). Participants ranged in age from 14.0 to 86.5 years $(M=42.5$ years, $S D=19.0)$, and $24.1 \%$ held a college or university degree. They were approximately stratified by gender $(50.3 \%$ men) and age (17\% were $14-18$ years of age, $15 \%$ were $19-29$ years of age, $14 \%$ were $30-39$ years of age, $16 \%$ were $40-49$ years of age, $15 \%$ were $50-59$ years of age, $16 \%$ were $60-70$ years of age, and $7 \%$ were $70-90$ years of age).

Procedure. The study began with an individual instruction and training session typically conducted in the participants' homes. Participants received mobile phones (Nokia E50) with Java software that controlled the participants' assessment schedule, presented items and tasks, and uploaded responses to a central server. Participants navigated and responded to the instrument using the mobile phone's joystick and keypad. During this first session, participants received extensive instructions and completed a sample trial of the questionnaire.

Following the instruction session, participants carried the phone with them at all times during three experience-sampling periods, each lasting 3 consecutive days. The experiencesampling periods covered a total of at least 6 weekdays (Monday through Friday) and 3 weekend days (Saturday and Sunday) and were separated by intervals of 6 days. On each experiencesampling day, six assessments were distributed over a 12-hr window, the start of which was chosen by the participants according to their personal waking habits. During each of the six 2-hr time periods within the participant's personal time window, one signal was scheduled randomly, with the provision that two adjacent measurement occasions were at least $15 \mathrm{~min}$ apart. If participants did not respond, they were reminded twice by auditory signals, occurring after 5 and after $10 \mathrm{~min}$. If there was still no response, the instrument closed after $15 \mathrm{~min}$, thus reducing participants' degree of freedom in determining when to answer the questions. On average, participants completed at least five of the six daily assessments on $90.7 \%$ of their assessment days $(S D=0.13)$. To obtain a sufficient number of assessments, experience-sampling periods were extended for a day if participants completed fewer than five assessments on a given day. Overall, $M=1.21(S D=1.71)$ of these extension days were scheduled per participant. Participants thus completed an average of 54.9 assessments $(S D=4.1)$. They were reimbursed with $100 €$ (approximately $\$ 150$ ). The ethics committee of the Max Planck Institute for Human Development approved the study.

Experience-sampling measures. At each of the experiencesampling assessments six times per day, participants answered a brief questionnaire containing, among other things, the following items.

Affective experience. Participants reported how angry, anxious, disappointed, and downcast they currently felt on a scale ranging from 0 (not at all) to 6 (very much). A multilevel confirmatory factor analysis conducted in Mplus (Muthén \& Muthén, 2008) attested good fit to a two-factor model in which angry and anxious loaded on one factor, and disappointed and downcast loaded on the other (comparative fit index $[\mathrm{CFI}]=.987$, rootmean-square error of approximation [RMSEA] $=.039), x^{2}=$ 32.56, $p<.001$. Ratings of angry and anxious were therefore averaged to yield an indicator of momentary high-arousing negative affect (multilevel reliability estimate $=.95$ ), and ratings of disappointed and downcast were averaged to yield an indicator of momentary low-arousing negative affect (multilevel reliability estimate $=.96$ ).

Unpleasant events. Participants indicated at each measurement occasion, whether they had experienced an unpleasant event since the last measurement (yes/no). If they indicated that something unpleasant had occurred, they were asked to indicate the life domain(s) this event affected (interpersonal, work, health, financial, future plans, daily hassles, or other; Almeida, Wethington, \& Kessler, 2002). Two dummy-coded variables were derived from these answers: "Circumscribed unpleasant event" indicated that participants reported an event that only affected one life domain ( 1 = had occurred, 0 = had not occurred), and "complex unpleasant event" indicated that participants reported an event that 
was related to more than one life domain $(1=$ had occurred, $0=$ had not occurred). ${ }^{1}$

Current activity and persons present as control variables. At each measurement occasion, participants also reported their current activity by choosing the appropriate response option(s) among work/school/study, chores/errands, leisure activity, doing nothing/ sleeping/watching TV, doctor visit/office run, conversation/visit, and other. They also indicated whether other persons were momentarily present by checking the appropriate response(s) among nobody, partner, family, friends, colleagues/fellow students, strangers, and other.

Analytic approach. As measurement occasions (Level 1) were nested within days (Level 2), which were nested within persons (Level 3), we specified three-level random coefficient models in hierarchical linear modeling (HLM; cf. Raudenbush, Bryk, \& Congdon, 2004), using full information maximum likelihood and robust standard error estimation. More specifically, highor low-arousing negative affect at a certain measurement occasion was predicted using the following equations:

Occasion level (Level 1)

$\mathrm{NA}_{\mathrm{ijk}}=\pi_{0 \mathrm{jk}}+\pi_{1 \mathrm{jk}}($ circumscribed event yes/no)

$$
+\pi_{2 \mathrm{jk}}(\text { complex event yes/no })+\mathrm{e}_{\mathrm{ijk}}
$$

Day level (Level 2)

$$
\begin{aligned}
& \pi_{0 \mathrm{jk}}=\beta_{00 \mathrm{k}}+\mathrm{r}_{0 \mathrm{jk}} \\
& \pi_{1 \mathrm{jk}}=\beta_{10 \mathrm{k}}+\mathrm{r}_{1 \mathrm{jk}} \\
& \pi_{2 \mathrm{jk}}=\beta_{20 \mathrm{k}}+r_{2 \mathrm{jk}}
\end{aligned}
$$

Person level (Level 3)

$$
\begin{aligned}
& \beta_{00 \mathrm{k}}=\gamma_{000}+\gamma_{001}(\text { age })+\mathrm{u}_{00 \mathrm{k}} \\
& \beta_{10 \mathrm{k}}=\gamma_{100}+\gamma_{101}(\text { age })+\mathrm{u}_{10 \mathrm{k}} \\
& \beta_{20 \mathrm{k}}=\gamma_{200}+\gamma_{201}(\text { age })+\mathrm{u}_{20 \mathrm{k}}
\end{aligned}
$$

On the level of measurement occasions (Level 1), circumscribed and complex unpleasant events were entered as two dummy-coded predictors, with situations without previous unpleasant events serving as reference category. Respective parameter estimates thus reflect average within-person differences between the level of negative affect reported in situations without prior occurrences of negative events (baseline) and the level of negative affect reported in situations with preceding circumscribed or complex events, respectively, assuming all other predictor variables to be zero. The age of participants was entered grand-mean centered on Level 3. The coefficient $\gamma_{000}$ reflects average negative affect of participants with average sample age at a measurement occasion when no unpleasant event had occurred previously, and $\gamma_{001}$ indicates the respective differential in "baseline negative affect" (i.e., in situations without an unpleasant event) for a 1-year increase in participants' age. $\gamma_{100}$ and $\gamma_{200}$ denote the average responding to circumscribed and complex unpleasant events (relative to situations without unpleasant events), respectively, for a person of average sample age. They can thus be interpreted as average unstandardized change scores. $\gamma_{101}$ and $\gamma_{201}$ reflect age differences in these "responding effects" (i.e., the respective differential for a 1-year increase in age). Model-estimated unstandardized change scores were standardized with age-specific standard deviations of the outcome to approximate standardized effect sizes (Hoffman \& Stawski, 2009; Wrzus, Denissen, \& Lüdtke, 2012). Random variance at each level is indicated by the coefficients e, r, and $u$. Present persons, current activity, and cumulative number of unpleasant events reported on the current day (i.e., how many unpleasant events had already been reported on that day up to the current situation) were entered as control variables at the occasion level (Level 1). The cumulative number of unpleasant events on the current day controlled for effects of increasing responding due to multiple unpleasant situations on a given day and was included as a control variable to account for differences in the daily prevalence of unpleasant events. ${ }^{2}$

In short, we compared within-person differences in negative affect after circumscribed or complex unpleasant events to a baseline when no unpleasant events occurred. This baseline seemed most suitable since it was controlled for contextual effects and thus reflected the average, that is, "normal" state of negative affect. Also, the unequal spacing of measurement occasions (with intervals ranging from few hours to several days) made other baseline operationalizations, such as comparisons to the previous measurement point, unfeasible. The unequal spacing of measurement occasions resulted from optimizing the study design to cover multiple assessments per day and to span several weeks. Second, at $22 \%$ of occasions with unpleasant events, another unpleasant event was reported at the previous measurement occasion. This further demonstrates the advantages of situations without previous unpleasant events compared to $\mathrm{T}-1$ measurement occasions as baseline measurements.

\section{Results}

The presentation of findings is organized as follows. We first report findings on age differences in the prevalence of unpleasant events. Following that, we analyze age-related differences in participants' psychological responding to circumscribed and complex unpleasant events. Descriptive information of, and correlations among, central study variables are summarized in Table 1.

Age-related differences in the prevalence of unpleasant events. The vast majority (91\%) of the participants reported occurrences of unpleasant events during the study interval. On

\footnotetext{
${ }^{1}$ We distinguished complex from circumscribed unpleasant events when more than one life domain is affected and do not distinguish further when two, three, or more life domains are affected because the average and the modal number were two affected life domains in both studies (see the Results sections). We favor this approach over the assessment of subjective severity because severity judgments differ with age (Stawski et al., 2008), such that age differences in affective responding based on age-varying subjective severity of unpleasant events would be difficult to interpret.

${ }^{2}$ At measurement occasions with unpleasant events, 0.22 hassles (person average) had occurred before the assessment that day (range $=0-1.88, S D=$ 0.27). This means that in most cases (i.e., in $77 \%$ of the measurement occasions with an unpleasant event), the current unpleasant event was not preceded by others. Since occasions with three or more prior unpleasant events were scarce ( $1.5 \%$ of occasions with unpleasant events), we repeated the analyses with a dummy-coded control variable instead of a control continuous variable for cumulative unpleasant events $(0=$ no unpleasant event occurred before this measurement occasion, 1 = one or more unpleasant events occurred). The results were comparable to the ones reported in Table 2.
} 
Table 1

Study 1: Descriptive Statistics and Intercorrelations of Central Study Variables

\begin{tabular}{|c|c|c|c|c|c|}
\hline \multirow[b]{2}{*}{ Variable } & \multirow[b]{2}{*}{$M(S D)$} & \multicolumn{4}{|c|}{ Pearson correlations } \\
\hline & & 1 & 2 & 3 & 4 \\
\hline 1. Age & $42.46(19.04)$ & & & & \\
\hline 2. Within-person average low-arousing negative affect & $0.75(0.70)$ & $-.14^{* *}$ & & & \\
\hline 3. Within-person average high-arousing negative affect & $0.67(0.54)$ & -.05 & $.76^{* * *}$ & & \\
\hline 4. $\%$ circumscribed unpleasant events ${ }^{\mathrm{a}}$ (affecting one life domain) & $0.08(0.07)$ & -.07 & $.23^{* *}$ & $.28^{* * *}$ & \\
\hline 5. \% complex unpleasant events ${ }^{\mathrm{a}}$ (affecting multiple life domains) & $0.02(0.03)$ & -.08 & $.17^{* *}$ & $.19^{* * *}$ & $.21^{*}$ \\
\hline
\end{tabular}

average, participants reported on $9.2 \%$ of the measurements they completed that an unpleasant event had occurred since the last measurement occasion $(S D=8.5$, range $=0 \%-71 \%)$. With higher age, participants tended to report slightly fewer unpleasant events $(r=-.09, p=.046)$. Participants classified unpleasant events most often as interpersonal (39\%), followed by work/school $(14 \%)$, daily hassles $(10 \%)$, health (8\%), finances $(6 \%)$, and future plans $(2 \%)$. On average $12.9 \%(S D=21.8)$ of the unpleasant events reported by a given person were complex, that is, affected multiple life domains (mode $=2, M=2.2$ life domains). The percentage of complex unpleasant events did not vary significantly with the participants' age $(r=-.07, p=.09)$.

Age-related differences in psychological responding to unpleasant events. Table 2 summarizes the parameter estimates of two multilevel models that predicted high- and low-arousing negative affect by age, occurrence of circumscribed and complex unpleasant events, and the respective interactions with age, controlling for other persons present and the participants' momentary activity. Whereas participants' age was not predictive of average reports of average high-arousing negative affect (feeling angry and anxious), participants tended to report generally less low-arousing negative affect (feeling downcast and disappointed) the older they were. We also tested for potential non-linear age effects; however, none were statistically significant $(p>.05)$.

The significant effects of circumscribed and complex events indicate that participants reported significantly more intense highand low-arousing negative affect when circumscribed and complex unpleasant events had occurred, compared to situations without previous occurrences of unpleasant events. These comparative increases in high- and low-arousing negative affect were significantly more pronounced after the occurrence of complex unpleasant events - post hoc comparison of slope coefficients for circumscribed and complex events: for high-arousing negative affect, $\chi^{2}(1)=10.61$, $p=.002$; for low-arousing negative affect, $\chi^{2}(1)=14.06, p<.001$. The average standardized change scores for increases related to circumscribed events were 1.1 and 1.0 standard deviation units for highand low-arousing negative affect, respectively. For increases related to complex events, the standardized effect size was 1.4 for lowarousing negative affect, whereas effect sizes for high-arousing negative affect varied with participants' age as indicated by the significant Age $\times$ Complex Unpleasant Event interaction.

Consistent with the overpowering hypothesis, this Age $\times$ Complex Unpleasant Event interaction indicates that the elevated higharousing negative affect after complex unpleasant events was more pronounced the older participants were. Simple-slope analysis revealed that increases in high-arousing negative affect after complex unpleasant events were significant for the whole age range of the sample. Age accounted for approximately $37 \%$ of the betweenperson variability in affective responding in high-arousing negative affect. Figure 1 illustrates predicted, standardized withinperson change scores in high-arousing negative affect for the minimum, mean, and maximum age in the investigated sample. The values denote the estimated effect sizes for differences in negative affect after unpleasant events occurred compared to measurement occasions without prior negative events. After the occur-

Table 2

Study 1: Age and Occurrences of Circumscribed and Complex Unpleasant Events as Predictors of High-and Low-Arousing Negative Affect (Unstandardized Parameters From Three-Level Multilevel Models)

\begin{tabular}{|c|c|c|}
\hline \multirow[b]{2}{*}{ Variable } & \multicolumn{2}{|c|}{ Negative affect } \\
\hline & High-arousing & Low-arousing \\
\hline Intercept & $0.66^{* * *}$ & $0.71^{* *}$ \\
\hline Age & $-0.002^{n s}$ & $-0.006^{* *}$ \\
\hline \multicolumn{3}{|l|}{ Occurrence of unpleasant events } \\
\hline Circumscribed (single domain) & $0.87^{* * *}$ & $0.94^{* *}$ \\
\hline Complex (multiple domains) & $1.13^{* * *}$ & $1.27^{* *}$ \\
\hline Age $\times$ Circumscribed Unpleasant Event & $0.002^{n s}$ & $-0.002^{n s}$ \\
\hline Age $\times$ Complex Unpleasant Event & $0.011^{*}$ & $-0.002^{n s}$ \\
\hline \multicolumn{3}{|l|}{ Control variables } \\
\hline $\begin{array}{l}\text { Cumulative number of unpleasant } \\
\text { events }^{\mathrm{a}}\end{array}$ & $0.07^{* *}$ & $0.15^{* *}$ \\
\hline Partner present ${ }^{\mathrm{b}}$ & $-0.06^{* * *}$ & $-0.04^{*}$ \\
\hline Family present ${ }^{\mathrm{b}}$ & $-0.02^{n s}$ & $-0.01^{n s}$ \\
\hline Friends present ${ }^{\mathrm{b}}$ & $-0.06^{* *}$ & $-0.10^{* *}$ \\
\hline Colleagues/students present ${ }^{\mathrm{b}}$ & $0.05^{n s}$ & $-0.001^{n s}$ \\
\hline Strangers present ${ }^{\mathrm{b}}$ & $0.05^{*}$ & $-0.01^{n s}$ \\
\hline Others present ${ }^{\mathrm{b}}$ & $0.05^{n s}$ & $-0.002^{n s}$ \\
\hline Work/school activity ${ }^{\mathrm{c}}$ & $0.01^{n s}$ & $-0.06^{*}$ \\
\hline Chores/errands ${ }^{\mathrm{c}}$ & $-0.04^{n s}$ & $-0.04^{n s}$ \\
\hline Leisure activity $^{\mathrm{c}}$ & $-0.15^{* * *}$ & $-0.11^{* *}$ \\
\hline Doing nothing/watching $\mathrm{TV}^{\mathrm{c}}$ & $-0.13^{* * *}$ & $-0.03^{n s}$ \\
\hline Doctor visit/office run $^{\mathrm{c}}$ & $0.07^{n s}$ & $0.04^{n s}$ \\
\hline Conversation/visit $^{\mathrm{c}}$ & $-0.10^{* *}$ & $-0.08^{* *}$ \\
\hline
\end{tabular}

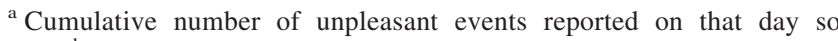
far. ${ }^{b}$ Reference category of nobody for people present. ${ }^{c}$ Reference category of other for activity. $n s>.05 .{ }^{*} p<.05$. ${ }^{* *} p<.01$. 


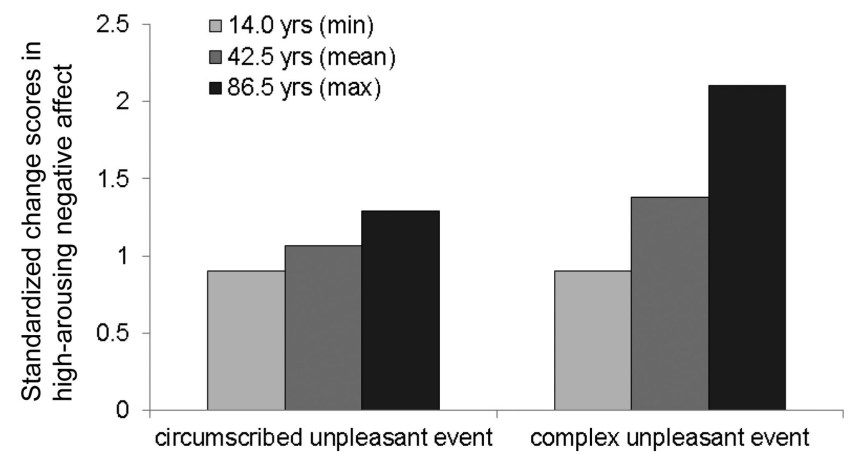

Figure 1. Study 1: Age differences in increased high-arousing negative affect when experiencing unpleasant events in daily life relative to situations without unpleasant events. Predicted change scores from multilevel modeling are shown, which are standardized with age-specific withinperson standard deviations of high-arousing negative affect.

rence of complex unpleasant events, high-arousing negative affect of the youngest participants was relatively increased (compared to baseline) by about 0.9 standard deviation units. In comparison, the respective effect sizes were larger for middle-age and oldest participants, namely 1.4 and 2.1 , respectively.

When predicting increased low-arousing negative affect, the Age $\times$ Complex Event interaction did not reach statistical significance. Similarly, the Age $\times$ Circumscribed Event interactions were not significant for high-arousing or for low-arousing negative affect. That is, consistent with our assumptions, there was no evidence of age differences in increased high- or low-arousing negative affect after circumscribed unpleasant events.

The significant effects of the cumulative number of unpleasant events indicate that both high- and low-arousing negative affect increased with every additional unpleasant event occurring on a given day. The size of these cumulative effects was small. This indicates that the strongest increases in negative affect were related to experiencing an unpleasant event and apart from that, having a stressful day related to small additional increases in negative affect.

To summarize, experiencing unpleasant events in daily life was related to both increased high- and increased low-arousing negative affect compared to situations with no previous unpleasant events. Increases of negative affect were more pronounced after complex unpleasant events, which affected multiple life domains, than after circumscribed unpleasant events that affected a single life domain. Importantly, and consistent with the overpowering hypothesis, we found no significant age differences in affective responding to circumscribed unpleasant events; yet, stronger increases in high-arousing negative affect after complex unpleasant events were observed the older the participants were.

\section{Study 2-Differences in Cardiovascular Responding to Unpleasant Events in Daily Life}

The aim of Study 2 was to investigate the overpowering hypothesis with respect to age differences in cardiovascular responding to unpleasant events in daily life. More specifically, we were interested in age-related differences in changes of heart rate variability, which indicates regulatory parasympathetic influences on the heart. We predicted everyday unpleasant events to be accom- panied by relatively lower heart rate variability (indicating higher stress) compared to situations without unpleasant events. We also expected an age-related increase in people's cardiovascular responding (more strongly decreased heart rate variability) to complex, but not to circumscribed, negative events. To investigate these predictions, we combined the mobile phone-based experience-sampling technique used in Study 1 with 24-hr ambulatory psycho-physiological monitoring of cardiovascular and physical activity in a subsample of the participants from Study 1.

\section{Method}

Participants. In contrast to Study 1, which was a multilocation study (see before), Study 2 was conducted exclusively in Berlin to accommodate the logistic requirements of the ambulatory psycho-physiological monitoring. Participants were therefore recruited from the 128 Berlin participants of Study 1. Of these, 92 (72\%) participants agreed to take part in Study 2. Participants were between 14.7 and 83.2 years of age $(M=42.4$ years, $S D=19.0)$. They were approximately stratified by gender ( $45 \%$ men) and age (11\% were 14-18 years of age, 19\% were 19-29 years of age, $17 \%$ were $30-39$ years of age, $15 \%$ were $40-49$ years of age, $13 \%$ were 50-59 years of age, $16 \%$ were $60-70$ years of age, and $8 \%$ were $70-90$ years of age). Cardiovascular data of three participants were unavailable because of technical problems $(n=1)$ or because cardiac arrhythmia made the electrocardiogram (ECG) measurements uninterpretable $(n=2)$. Participants of Study 2 did not differ from Berlin participants of Study 1 who did not take part in Study 2 regarding their age, gender, or the number of complex unpleasant events reported in Study 1 (all $p$ s $>$.20). The only difference between both subsamples involved the number of circumscribed events reported in Study 1: Study 1 participants from Berlin who did not participate in Study 2 reported a slightly lower prevalence of circumscribed unpleasant events in Study 1 than those participants from Berlin who did participate in Study $2-5.4 \%$ versus $9.0 \%$ of measurement occasions, respectively, $t(126)=2.56, p=.01$. This suggests that participants with more unpleasant events in Study 1 were not more likely to decline participation in Study 2 and that overall the sample of Study 2 is highly similar to the original Berlin sample.

Procedure. Study 2 took place, on average, 8.4 months after Study $1(S D=0.9)$. Participants came to the laboratory on Day 1 to receive instructions and the technical devices. After explaining the purpose and procedure of the study and the ECG assessment, and receiving consent from the participant, the portable biosignal recorder (Varioport from Becker Meditec) as well as ECG and acceleration sensors were attached. Trained experimenters placed surface Arbo one-way ECG electrodes on the participant's thorax in the standard three-lead chest configuration (Huppelsberg \& Walter, 2005): (a) at the right clavicle, below the lowest left rib; (b) at the outer axillary line; and (c) at the middle axillary line. The raw ECG signals were recorded at a sampling rate of $256 \mathrm{~Hz}$. To measure participants' physical activity as a control variable, a threedimensional acceleration sensor was placed at the sternum, and a one-dimensional acceleration sensor was attached at the right thigh. The acceleration signals were recorded at a sampling rate of $64 \mathrm{~Hz}$.

After answering a few questionnaires and completing a brief experiment not relevant here, participants were released to their daily life for, on average, $25.8 \mathrm{hr}(S D=0.8 \mathrm{hr}$, minimum $=22.3 \mathrm{hr}$, 
maximum $=29.8 \mathrm{hr}$ ). Physiological measures were continuously recorded during the ambulatory assessment phase. Participants answered experience-sampling questionnaires presented via the same mobile phones as in Study 1 (Nokia E50). The same Java software as in Study 1 controlled the schedule of the experience sampling and presented items on the mobile phone screen. On average, participants answered seven assessments $\left(S D=0.8, r_{\text {age }}=.05, p=.31\right)$ during their waking hours of the 2 assessment days. The experiencesampling procedure scheduled one random assessment for each of the six subsequent 2-hr windows, ensuring that measurement occasions were at least 15 min apart. Participants received $150 €$ (approximately \$200) as reimbursement. The ethics committee of the Max Planck Institute for Human Development approved the study.

Measures. The measures for affective experience, occurrence of unpleasant events, as well as current activities and persons present were the same as in Study 1.

Cardiovascular activity. To analyze heart rate variability in ECG recordings, the standard time-domain measure RMSSD was used (Malik et al., 1996), which was calculated as the root of the mean squared differences between successive interbeat intervals of the ECG curve. The RMSSD measure is an estimate of short-term components of heart rate variability. It correlates very highly with short-term components of heart rate variability derived from spectral analyses but is, unlike measures derived from spectral analyses, also applicable to short ECG recording intervals of less than 2 min (Denver, Reed, \& Porges, 2007; Goedhart, Van Der Sluis, Houtveen, Willemsen, \& De Geus, 2007; Malik et al., 1996). It is therefore very suitable for our purposes of measuring an indicator of parasympathetic control (Denver et al., 2007; Malik et al., 1996). RMSSD values were computed for the time period of answering a given experience-sampling questionnaire, which lasted on average $246 \mathrm{~s}(S D=88 \mathrm{~s})$. RMSSD values were screened for age-specific outliers (Malik et al., 1996; Umetani, Singer, McCraty, \& Atkinson, 1998) and were log-transformed (natural logarithm) to reduce slight left skewness.

Physical activity. To control for the influence of physical activity in cardiovascular measures, activity values were computed as follows (Fahrenberg, Foerster, Smeja, \& Mueller, 1997; Mathie, Coster, Lovell, \& Celler, 2004): First values from the two acceleration sensors were detrended to remove any linear drift of measurements over time and corrected for the influence that gravitational force exerted on the acceleration sensors depending on the posture of the person. The absolute values of these adjusted measurements were summed for the duration of each experiencesampling measurement occasion and divided by the length of participants' responding to the respective measurement. This yielded an indicator of participants' average physical activity per minute while responding to the experience-sampling questionnaire. Minute average values were log-transformed to normalize left-skewed distribution, which was due to a larger number of measurement occasions with little physical activity.

Health and physical fitness-person variables. Following the ambulatory monitoring, participants came to the laboratory on Day 2. The ambulatory monitoring system was detached, and participants were asked to answer questionnaires on potential previous illnesses, medication, and general physical fitness. We derived an indicator of prior cardiac illness from answers regarding previous cardiovascular illnesses, such as high or low blood pressure, coronary heart illnesses, heart attack, arrhythmia, or inflammatory cardiac illnesses. This indicator was dummy-coded with " 1 " indicating a previously diagnosed cardiac illness and " 0 " indicating no previously diagnosed cardiac illnesses, which applied to $88 \%$ of the participants. Participants also reported the name and the type of any medication they took regularly and also on the day of the data assessment. We classified the medication as having an effect on heart rate variability $(1=$ yes, $0=$ no; the latter being the case for $86 \%$ of participants) based on patient information sheets and with the support of a physician regarding unclear cases. As an indicator of participants' regular fitness activities, we used the sum of hours spent on physical activities during a typical week, such as walking, gardening, swimming, biking, and dancing $(M=2.80, S D=3.44)$. In addition, participants' body mass index $(M=26.0, S D=5.3)$ was calculated by dividing laboratory measurements of participants' weight in kilograms by their squared height in meters.

Analytic approach. As measurement occasions (Level 1) were nested within persons (Level 2), we specified two-level random coefficient models in HLM (Raudenbush et al., 2004), using full information maximum likelihood and robust standard error estimation. More specifically, average heart rate variability (lnRMSSD) during a given experience-sampling measurement was predicted using the following equations:

Occasion level (Level 1)

$$
\begin{aligned}
\operatorname{lnRMSSD} & =\beta_{0 \mathrm{j}}+\beta_{1 \mathrm{j}}(\text { circumscribed event yes } / \mathrm{no}) \\
& +\beta_{2 \mathrm{j}}(\text { complex event yes } / \mathrm{no}) \\
& +\beta_{3 \mathrm{j}}(\text { physical activity }) \\
& +\beta_{4 \mathrm{j}}(\text { time of day })+\mathrm{r}_{\mathrm{ij}}
\end{aligned}
$$

Person level (Level 2)

$$
\begin{aligned}
& \beta_{0 \mathrm{j}}=\gamma_{00}+\gamma_{01}(\text { age })+\gamma_{02}\left(\text { age }^{2}\right)+\mathrm{u}_{0 \mathrm{j}} \\
& \beta_{1 \mathrm{j}}=\gamma_{10}+\gamma_{11}(\text { age })+\mathrm{u}_{1 \mathrm{j}} \\
& \beta_{2 \mathrm{j}}=\gamma_{20}+\gamma_{21}(\text { age })+\mathrm{u}_{2 \mathrm{j}} \\
& \beta_{3 \mathrm{j}}=\gamma_{30}+u_{3 \mathrm{j}} \\
& \beta_{4 \mathrm{j}}=\gamma_{40}+\mathrm{u}_{4 \mathrm{j}}
\end{aligned}
$$

On the level of measurement occasions (Level 1), circumscribed and complex unpleasant events were entered as two dummy-coded predictors. Consequently, situations without previous unpleasant events again served as reference category. That is, we analyzed within-person differences in heart rate variability in situations after circumscribed or complex events compared to situations in which no unpleasant event had occurred (individual baseline). Physical activity during the given measurement occasion and time of day were entered as control variables on Level 1 (both grand-mean centered). Age of participants was grand-mean centered and included on Level 2. The coefficient $\gamma_{\mathrm{oo}}$ denotes the average level of heart rate variability (lnRMSSD) at measurement occasions before which no unpleasant event had occurred previously, assuming all other predictors to be at the sample mean; $\gamma_{10}$ reflects the average difference in heart rate variability (compared to situations without previous unpleasant events) after a circumscribed unpleasant event had occurred (assuming all other predictors to be at the sample 
mean); $\gamma_{20}$ represents the respective difference after the occurrence of complex unpleasant events that related to multiple life domains compared to the individual baseline; and $\gamma_{11}$ and $\gamma_{21}$ reflect age differences in these respective effects. $\gamma_{10}$ and $\gamma_{20}$ can be interpreted as average unstandardized change scores, and we computed standardized effect sizes by multiplying unstandardized change scores with the inverse of age-specific standard deviations of RMSSD (Hoffman \& Stawski, 2009; Wrzus et al., 2012). Random variance at each level is indicated by the coefficients $r$ and $u$.

\section{Results}

Age-related differences in the prevalence of unpleasant events. About $40 \%$ of participants reported unpleasant events during the 24-hr study period. These participants were not significantly clustered in specific age groups, $\chi^{2}(6)=6.97, p=.32$; that is, they were about evenly distributed across all investigated age groups. Unpleasant events were reported, on average, on $8.2 \%$ of the measurement occasions obtained from a given participant $(S D=12.6$, range $=0 \%-57 \%)$. Participants' age was not significantly associated with the percentage of measurement occasions with unpleasant events reported $(r=-.16, p=.13)$. Participants classified the reported unpleasant events most often as interpersonal (36\%), followed by work-related (27\%), daily issues (11\%), health-related $(10 \%)$, and other $(6 \%)$. On average, $11.7 \%(S D=30.4)$ of the unpleasant events reported by a given person were complex, that is, affected multiple life domains (mode $=2, M=2.2$ ). The percentage of complex unpleasant events also did not vary significantly with the participants' age $(r=.17, p=.35)$. Table 3 provides descriptive information on the central variables of Study 2.

Age-related differences in cardiovascular responding to unpleasant events. The left column of Table 4 summarizes parameter estimates of a multilevel model predicting momentary heart rate variability (lnRMSSD) by age, the occurrence of circumscribed and complex unpleasant events, and the respective interactions with age, controlling for the level of physical activity during the experience sampling report, and time of day. The average heart rate variability at occasions with no previous hassle was predicted by linear as well as quadratic age effects. It followed a U-shaped curve and was somewhat lower for participants in middle adulthood compared to younger and older participants.

Consistent with the overpowering hypothesis, there were significant interactions between age and the occurrences of circumscribed or complex unpleasant events when predicting fluctuations in heart rate variability (see Table 4 and Figure 2): With higher age, cardiovascular responses were less pronounced when reporting circumscribed unpleasant events and were more pronounced when encountering complex unpleasant events, both relative to situations without previous unpleasant events. To follow up on these age interactions, simple-slope analyses revealed that decreases in heart rate variability (indicating higher stress responding) to circumscribed unpleasant events were less pronounced with higher age up to the age of 36.8 years. In participants older than 36.8 years, occurrences of circumscribed unpleasant events were no longer significantly related to changes in heart rate variability. In contrast, occurrences of complex unpleasant events were predictive of larger decreases in heart rate variability relative to the individual baseline the older participants were. Simple-slope analyses revealed that this decrease in heart rate variability associated with complex unpleasant events was statistically significant for people 41.5 years of age and older. These effects remained robust when additionally controlling for other persons present, the activity participants momentarily engaged in, medication, cardiac illnesses, regular sport activity, and body mass index. Figure 2 illustrates predicted, standardized within-person change scores in heart rate variability for the minimum, mean, and maximum age of the investigated sample. The standardized change scores denote the estimated effect sizes for differences in heart rate variability after a circumscribed or complex unpleasant event occurred compared to situations without previous unpleasant events (baseline).

We next addressed the concern that the observed age effects might be due to age differences in psychological responses to unpleasant events. We re-ran the analyses of Model A but additionally included high- and low-arousing negative affect and the interactions with age as model predictors. The age moderations in the effects of circumscribed and complex unpleasant events on heart rate variability remained significant (see Model B in Table 4). This indicates that age differences in cardiovascular responding to unpleasant events were not attributable to age differences in the accompanying negative affect.

To summarize, heart rate variability decreased after experiencing unpleasant events in daily life, compared to situations without a preceding unpleasant event. This indicates a physiological stress response and was especially pronounced for experiences of complex unpleasant events. Importantly, and consistent with the overpowering hypothesis and results from Study 1, we found stronger responding after complex unpleasant events the older the partici-

Table 3

Study 2: Descriptive Statistics and Intercorrelations of Central Study Variables

\begin{tabular}{lcrrr} 
& & & \multicolumn{2}{c}{ Pearson correlations } \\
\cline { 3 - 6 } \multicolumn{1}{c}{ Variable } & $M(S D)$ & 1 & 2 & 3 \\
\hline 1. Age & $41.30(18.26)$ & & & \\
2. Within-person average heart rate variability (lnRMSSD) & $3.26(0.62)$ & $-.46^{* *}$ & & \\
3. \% circumscribed unpleasant events ${ }^{\mathrm{a}}$ (affecting one life domain) & $0.07(0.12)$ & -.16 & .07 & \\
4. $\%$ complex unpleasant events $^{\mathrm{a}}$ (affecting multiple life domains) & $0.01(0.04)$ & .02 & -.06 & .07 \\
\hline
\end{tabular}

Note. $\quad N=89$ due to unavailable cardiovascular data of three participants. $\operatorname{lnRMSSD}=\log$-transformed root of mean squared difference of successive heart beats.

a Relative to a given participant's total number of measurements.

** $p<.01$. 
Table 4

Study 2: Age and Occurrences of Circumscribed and Complex Unpleasant Events as Predictors of Heart Rate Variability (Unstandardized Parameter From Two-Level Multilevel Models)

\begin{tabular}{|c|c|c|}
\hline \multirow[b]{2}{*}{ Variable } & \multicolumn{2}{|c|}{$\begin{array}{l}\text { Heart rate variability } \\
\quad \text { (lnRMSSD) }\end{array}$} \\
\hline & Model A & Model B \\
\hline Intercept & $3.05^{\text {*** }}$ & $3.17^{* * *}$ \\
\hline Age & $-0.018^{* *}$ & $-0.014^{* *}$ \\
\hline $\mathrm{Age}^{2}$ & $0.001^{*}$ & $0.001^{*}$ \\
\hline \multicolumn{3}{|l|}{ Occurrence of unpleasant events } \\
\hline Circumscribed (single domain) & $-0.09^{n s}$ & $-0.06^{n s}$ \\
\hline Complex (multiple domains) & $-0.25^{* * *}$ & $-0.20^{n s}$ \\
\hline Age $\times$ Circumscribed Unpleasant Event & $0.006^{*}$ & $0.009^{*}$ \\
\hline Age $\times$ Complex Unpleasant Event & $-0.011^{* *}$ & $-0.009^{*}$ \\
\hline \multicolumn{3}{|l|}{ Control variables: Occasion level } \\
\hline Time of day & $-0.007^{n s}$ & $-0.006^{n s}$ \\
\hline Momentary level of physical activity & $-0.15^{* *}$ & $-0.13^{* *}$ \\
\hline Negative affect: Low-arousing & & $-0.02^{n s}$ \\
\hline Negative affect: High-arousing & & $-0.003^{n s}$ \\
\hline Age $\times$ Negative Affect: Low-arousing & & $-0.003^{n s}$ \\
\hline Age $\times$ Negative Affect: High-arousing & & $0.0003^{n}$ \\
\hline Partner present ${ }^{\mathrm{a}}$ & & $0.002^{n s}$ \\
\hline Family present ${ }^{\mathrm{a}}$ & & $-0.07^{n s}$ \\
\hline Friends present ${ }^{\mathrm{a}}$ & & $0.003^{n s}$ \\
\hline Colleagues/students present ${ }^{\mathrm{a}}$ & & $0.03^{n s}$ \\
\hline Strangers present $\mathrm{a}^{\mathrm{a}}$ & & $-0.22^{* *}$ \\
\hline Others present ${ }^{\mathrm{a}}$ & & $0.05^{n s}$ \\
\hline Work/school activity ${ }^{\mathrm{b}}$ & & $0.05^{n s}$ \\
\hline Chores/errands ${ }^{\mathrm{b}}$ & & $-0.05^{n s}$ \\
\hline Leisure activity $^{\mathrm{b}}$ & & $-0.08^{n s}$ \\
\hline Doing nothing/watching $\mathrm{TV}^{\mathrm{b}}$ & & $0.06^{n s}$ \\
\hline Conversation/visit ${ }^{\mathrm{b}}$ & & $0.04^{n s}$ \\
\hline \multicolumn{3}{|l|}{ Control variables: Person level } \\
\hline Cardiac medication & & $0.15^{n s}$ \\
\hline Cardiac illness & & $-0.61^{n s}$ \\
\hline Physical fitness & & $-0.01^{n s}$ \\
\hline Body mass index & & $-0.02^{* *}$ \\
\hline
\end{tabular}

Note. $\operatorname{lnRMSSD}=\log$-transformed root of mean squared difference of successive heart beats.

${ }^{\mathrm{a}}$ Reference category of nobody for people present. $\quad{ }^{\mathrm{b}}$ Reference category of other, doctor visit for activity did not occur.

$n s>.05 . \quad * p<.05 .{ }^{* * *} p<.01$.

pants were. Results further indicated less pronounced responding with higher age after circumscribed unpleasant events.

\section{Discussion}

The purpose of this research was to contribute to a better understanding of age-related differences in affective responding to unpleasant events, focusing on the age range from adolescence to old age. Some lines of previous research have suggested that affective responding should increase throughout adulthood because age-related declines in cognitive competencies diminish people's affective abilities as well (Labouvie-Vief, 2003; Labouvie-Vief et al., 2007). Other researchers have held the contrary position and claimed that affective responding should decrease with age because life experience and higher motivation to maximize emotional well-being lead to improved ability to control affective reactions to unpleasant situations (Carstensen \& Charles, 1998; Gross et al., 1997). We proposed and tested the overpow- ering hypotheses in two studies as a possible explanation for the inconsistent pattern of findings to date, hoping to bridge the apparently opposing theoretical stances. Below, we discuss the findings of the two studies and explain how they complement each other and relate to previous studies. Then, we discuss how these findings might contribute to the understanding of age-related differences in affect regulation.

\section{Age-Related Differences in Affective Responding to Circumscribed and Complex Unpleasant Events}

Study 1 showed that unpleasant events in daily life elicited highand low-arousing negative affect that was more intense relative to negative affect in situations without prior unpleasant events. As expected, this relatively increased negative affect was more pronounced after complex unpleasant events that affected multiple life domains than after circumscribed unpleasant events that affected a single life domain only. This finding supports our assumption that the complexity of unpleasant situations is a situational characteristic that contributes to intra-individual differences in affective responses-in addition to other characteristics that have been proposed, for example, by previous stress research, such as the predictability, ambiguity, or novelty of the situation (Lazarus \& Folkman, 1984).

In accordance to the overpowering hypothesis, affective responding with respect to high- (but not low-) arousing negative affect to complex unpleasant events was more pronounced the older participants were. This concurs with previous studies on age differences in daily reactivity to severe unpleasant events (Mroczek \& Almeida, 2004; Sliwinski et al., 2009). The previously reported increases in negative affect, however, were considerably smaller compared to the increase of more than one scale point we observed in Study 1 reported here. Although the unstandardized coefficients are difficult to compare across studies because they stem from different items and scales, it is possible that end-of-day assessments underestimate the heightened negative affect in response to daily hassles. Underestimation could be due to retrospective memory biases that may additionally differ between participants of different age groups. For example, we did not observe

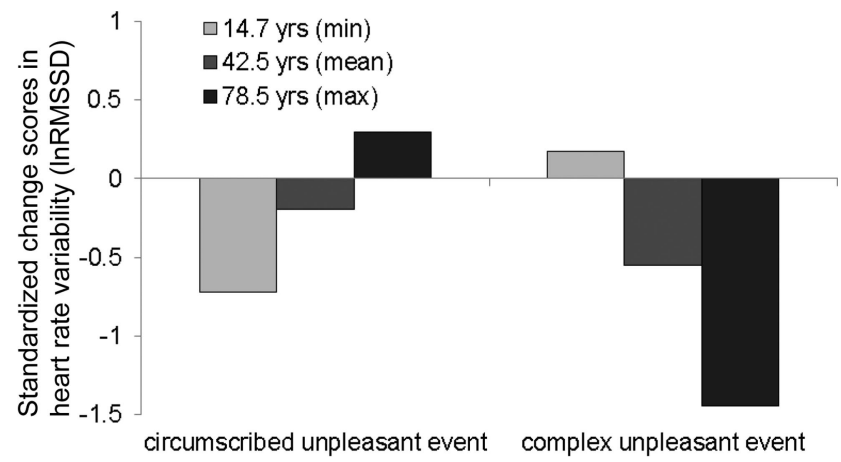

Figure 2. Study 2: Age differences in alterations of heart rate variability after unpleasant events occurred in daily life relative to situations without unpleasant events. Predicted change scores from multilevel modeling, which are standardized with age-specific within-person standard deviations of heart rate variability (log-transformed root of mean squared difference of successive heart beats [lnRMSSD]). 
less pronounced immediate affective responding with higher age after circumscribed events as sometimes reported in studies using end-of-day assessments (Birditt et al., 2005). This finding in endof-day assessment approaches could be due to older participants retrospectively recalling negative events as less negative than younger people (Charles, 2010; Levine \& Bluck, 1997). This problem is circumvented in repeated momentary experience sampling as used in the present research. The finding of similar affective responding to circumscribed unpleasant events across different age groups is consistent with the idea that the ability to regulate one's affective reactions is preserved throughout adulthood, as long as the affect-eliciting event remains manageable within the limits of the individual's capacities (see also Charles, 2010, for a similar argument). Thus, we argue that end-of-day assessments may underestimate the immediate effects of unpleasant events, and especially so for older adults.

In agreement with our hypothesis, more pronounced affective responding to complex unpleasant events with higher age was restricted to high-arousing negative affect-that is, anxiousness and anger - and was not evident for low-arousing negative affect. Immediate reactions to unpleasant events that involve arousing affect facets might be particularly relevant at higher ages when negative information is generally perceived as more arousing (Keil \& Freund, 2009). Furthermore, it has been proposed that higharousing unpleasant affect is increasingly problematic to manage with higher age because down-regulation physiological arousal becomes more difficult (Charles, 2010; Keil \& Freund, 2009). This underlines our assumption that complex unpleasant events that elicit highly arousing negative affect are more difficult to handle with higher age.

The findings of Study 2 supported and further extended the results of Study 1 with respect to parasympathetic responding to unpleasant events. Consistent with our findings in Study 1 and in line with the overpowering hypothesis, we found that with higher age, participants' responding in heart rate variability was stronger after experiencing complex unpleasant events that affected multiple life domains. Interestingly, we also found that the older the participants were, the weaker their heart rate variability responding was after experiencing circumscribed unpleasant events that concerned single life domains only. These findings again confirm the idea that age differences in affective responses to unpleasant situations depend on how demanding the event is.

These results also speak against the argument of a generalized age-related decline in cardiovascular flexibility (Charles, 2010; Levenson, 2000; Pugh \& Wei, 2001). The assumption of a decreased cardiovascular flexibility disagrees with the fact that, within the same sample, changes in heart rate variability were either more or less pronounced the older participants were, depending on the complexity of the unpleasant situation. Likewise, a recent meta-analysis on age-related differences on physiological responding showed that responsiveness reflected in heart rate changes decreases with age, but responsiveness reflected in changes in systolic blood pressure increases (Uchino et al., 2010). These two latter measures are differently affected by illnessrelated changes - for example, arteriosclerosis - and are differently sensitive to the individual's attempts to regulate their reactions to unpleasant events (Ferrari, Radaelli, \& Centola, 2003; Uchino et al., 2010). Uchino et al. (2010) argued that future studies should take into account associations with subjective experiences and should investigate affective responding outside laboratory contexts. Laboratory contexts might also limit older people's use of their preferred (and maybe practiced) affect-regulatory strategies (Carstensen, Isaacowitz, \& Charles, 1999).

We addressed both of these calls for research in our studies. Furthermore, we focused on heart rate variability as an indicator of cardiovascular activity that is predominantly under parasympathetic influence and thus unaffected by age-related changes in blood vessels (e.g., arteriosclerosis; Ferrari et al., 2003; Folkow \& Svanborg, 1993). High-frequency heart rate variability as an indicator of parasympathetic activity is assumed to be sensitive to the physiological manifestation of affect regulation (Berntson et al., 1997; Porges et al., 1994). Decreases in heart rate variability indicate the withdrawal of the homeostatic parasympathetic influence (Appelhans \& Luecken, 2006; Berntson et al., 1997). Thus, age-related attenuation of the withdrawal after circumscribed unpleasant events invites the interpretation that with higher age, people are better able to maintain the balancing effect of the parasympathetic nervous system in response to unpleasant events, provided the consequences of the event are limited.

Findings of both studies reported here show that age differences in affective responses to unpleasant events varied with the demand complexity of the unpleasant event, which had not been addressed empirically to date. A possible interpretation for this pattern of findings is based on the assumption that affective reactions to unpleasant events are shaped by the effectiveness with which people regulate their emotions in the face of adversity. Effective affect regulation has been proposed to require cognitive resources (Ochsner \& Gross, 2004; Richards \& Gross, 1999). Affect regulation in the face of complex adversity might thus overtax older adults' available fluid-cognitive capacity, which declines throughout adulthood (Ferrer-Caja et al., 2002; Heckhausen, Wrosch, \& Schulz, 2010; Verhaeghen \& Salthouse, 1997). Importantly, our findings show that physiological responding to circumscribed unpleasant events decreased with age, whereas psychological responding to such events showing no age associations suggests that older adults are just as - or perhaps even more-motivated and able to remain relatively calm in the face of adversities as long as these do not exceed their available resources (Kunzmann \& Richter, 2009). Drawing an analogy to cognitive development, such circumscribed events could describe situations where people show their usual or "baseline" performance, whereas responses to complex unpleasant events might reflect individual's "maximum levels" of affect regulation in analogy to maximum performance levels in complex cognitive tasks (Baltes, 1987). Therefore, focusing on differences in complexity of unpleasant events could provide the means for "testing-the-limits" of people's capacity for affect regulation similarly to studying limits of cognitive plasticity (Baltes, 1987; Kliegl et al., 1989).

\section{Strengths, Caveats, and Future Directions}

Our methodological approach of repeatedly sampling both psychological and physiological responses to unpleasant events occurring in people's daily lives at short time intervals accounted for the multi-dimensionality of affective experiences, maximized the ecological validity of our assessments, and diminished the time between the occurrence of the event and the assessment of affective responses. The latter is a methodological improvement over 
previous studies using end-of-day reports. In addition, our dataanalytic approach of specifying three-level multilevel models with observations nested within days nested within individuals took into account the possibility that nightly rests can serve as a natural emotion regulator (Minkel et al., 2012; Walker \& van der Helm, 2009). and, thus, delimit the interpretability of comparisons of affective states within individuals from one day to the next.

In the analyses reported in this article, we compared situations with prior negative events-either related to a single or multiple life domains - to situations without such events. The latter situations can be viewed as "normal states" because they accounted for about $90 \%$ of the measurement occasions in both studies, and served as a baseline in our analyses. We agree that other baselines, such as the previous measurement occasion or the average of all measurement occasions, are conceivable as well. However, in our view, the baseline used in the present study is particularly well suited to address the main research questions of this article: How do subjective and physiological states differ between situations in which unpleasant events had occurred versus had not occurred, and how are these differences modulated by people's age?

Despite these various strengths of our studies, a few limitations need to be mentioned. First, the cross-sectional design of the present studies leaves open the question whether the observed age-related differences correspond to intraindividual change as people age (Lindenberger, von Oertzen, Ghisletta, \& Herzog, 2011). Longitudinal investigations are necessary to investigate this question in the future. Another limitation of this research is its correlational nature, which prohibits conclusions about causality. We focused on heart rate variability as indicator of physiological responding, as this measure has been associated with psychological regulatory attempts (Appelhans \& Luecken, 2006; Berntson et al., 1997; Porges et al., 1994). The chosen operationalization of heart rate variability amplitude, RMSSD, proved to be a valid indicator of parasympathetic activity without controlling breathing (Denver et al., 2007). Although the need to control for breathing frequency is still under debate (cf. Denver et al., 2007; Grossman $\&$ Taylor, 2007), Denver et al. (2007) as well as our own work ${ }^{3}$ showed that RMSSD is largely independent of breathing frequency in a variety of situations. Heart rate variability amplitude can be assessed easily and reliably in ambulatory monitoring, in contrast to cortisol responses or changes in electrodermal activity, which have also been shown to be related to affective responses (Graham, Christian, \& Kiecolt-Glaser, 2006; Kreibig, 2010). However, physiological responding to unpleasant experiences is obviously multi-faceted. Thus, our conclusions on age differences in physiological responding to differently complex unpleasant events are restricted to heart rate variability as a selected indicator of physiological reactivity among others. Finally, our interpretations of findings involve the assumption that differences in affective responding to unpleasant events reflect differences in attempts to regulate one's affective experiences during stressful situations. These regulatory attempts, however, were not directly assessed in our studies. This will require implementation of suitable experimental paradigms in the future.

\section{Summary and Conclusion}

Focusing on a wide age range from adolescence to old age, we conducted two studies to investigate age-related differences in psychological and physiological responding to unpleasant events occurring in people's daily lives and natural environments, using momentary ecological assessment methods. Consistent with the overpowering hypothesis, our findings show that when dealing with complex unpleasant events that affect multiple life domains, both psychological and cardiovascular responding to unpleasant events were more pronounced with higher age. When dealing with circumscribed unpleasant events, however, no age differences in psychological responding were observed, and cardiovascular responding was even less pronounced the older the participants were.

These findings show that taking the demand complexity of affect-eliciting events into account may bridge theoretical predictions that appear to oppose at first glance and that derive from theoretical perspectives on socio-emotional selectivity (Carstensen et al., 2000) and on dynamic integration (Labouvie-Vief, 2003). On the one hand, our findings regarding equal or even lower responding of older compared to younger individuals to circumscribed unpleasant events are in line with the idea of the former position: With age, people might become increasingly motivated, and with experience perhaps even better at maximizing their emotional well-being (Charles, 2010; Isaacowitz, Toner, Goren, \& Wilson, 2008; Scheibe \& Blanchard-Fields, 2010). However, this might apply only as long as these situations do not overtax the available capacities. On the other hand, our findings of age-related increases in both psychological and physiological responding to complex unpleasant events are compatible with the idea that regulating one's affective responses in complex unpleasant situations becomes more difficult with age. Regulatory efforts are cognitively demanding (Kunzmann \& Richter, 2009; Richards \& Gross, 1999), and as fluidcognitive resources decline in later life (Ferrer-Caja et al., 2002; Verhaeghen \& Salthouse, 1997), handling one's affective responses may thus overburden older individuals in demanding situations. We conclude that the overpowering hypothesis can bridge currently opposing positions regarding age differences in affective responding by considering the complexity of the situation.

\footnotetext{
${ }^{3}$ Additional laboratory data from the 92 participants of Study 2 showed that across various activities the average correlation between RMSSD and breathing frequency was low and statistically nonsignificant-for example, for walking, climbing stairs, and standing: $r_{\text {average }}=-.04, p>.10$; for still postures such as standing, sitting, and lying supine: $r_{\text {average }}=-.10, p>$ .10. More details are available from the first author upon request.
}

\section{References}

Almeida, D. M., Wethington, E., \& Kessler, R. C. (2002). The Daily Inventory of Stressful Experiences: An interview-based approach for measuring daily stressors. Assessment, 9, 41-55.

Appelhans, B. M., \& Luecken, L. J. (2006). Heart rate variability as an index of regulated emotional responding. Review of General Psychology, 10, 229-240. doi:10.1037/1089-2680.10.3.229

Bäckman, L., \& Molander, B. (1986). Adult age differences in the ability to cope with situations of high arousal in a precision sport. Psychology and Aging, 1, 133-139. doi:10.1037/0882-7974.1.2.133

Baltes, P. B. (1987). Theoretical propositions of life-span developmental psychology: On the dynamics between growth and decline. Developmental Psychology, 23, 611-626. doi:10.1037/0012-1649.23.5.611

Baltes, P. B., \& Kliegl, R. (1992). Further testing of limits of cognitive plasticity: Negative age differences in a mnemonic skill are robust. Developmental Psychology, 28, 121-125. doi:10.1037/00121649.28.1.121 
Berntson, G. G., Bigger, J. T., Jr., Eckberg, D. L., Grossman, P., Kaufmann, P. G., Malik, M., ... van der Molen, M. W. (1997). Heart rate variability: Origins, methods, and interpretive caveats. Psychophysiology, 34, 623-648. doi:10.1111/j.1469-8986.1997.tb02140.x

Birditt, K. S., Fingerman, K. L., \& Almeida, D. M. (2005). Age differences in exposure and reactions to interpersonal tensions: A daily diary study. Psychology and Aging, 20, 330-340. doi:10.1037/0882-7974.20.2.330

Brehmer, Y., Li, S. C., Müller, V., von Oertzen, T., \& Lindenberger, U. (2007). Memory plasticity across the life span: Uncovering children's latent potential. Developmental Psychology, 43, 465-478. doi:10.1037/ 0012-1649.43.2.465

Brose, A., Schmiedek, F., Lövdén, M., \& Lindenberger, U. (2011). Normal aging dampens the link between intrusive thoughts and negative affect in reaction to daily stressors. Psychology and Aging, 26, 488-502. doi: 10.1037/a0022287

Burg, M. M., \& Pickering, T. G. (2011). The cardiovascular system. In R. J. Contrada \& A. Baum (Eds.), The handbook of stress science: Biology, psychology, and health (pp. 37-45). New York, NY: Springer.

Carstensen, L. L. (1992). Social and emotional patterns in adulthood: Support for socioemotional selectivity theory. Psychology and Aging, 7, 331-338. doi:10.1037/0882-7974.7.3.331

Carstensen, L. L., \& Charles, S. T. (1998). Emotion in the second half of life. Current Directions in Psychological Science, 7, 144-149. doi: 10.1111/1467-8721.ep10836825

Carstensen, L. L., Isaacowitz, D. M., \& Charles, S. T. (1999). Taking time seriously: A theory of socioemotional selectivity theory. American Psychologist, 54, 165-181. doi:10.1037/0003-066X.54.3.165

Carstensen, L. L., Pasupathi, M., Mayr, U., \& Nesselroade, J. R. (2000). Emotional experience in everyday life across the adult life span. Journal of Personality and Social Psychology, 79, 644-655. doi:10.1037/00223514.79.4.644

Charles, S. T. (2010). Strength and vulnerability integration: A model of emotional well-being across adulthood. Psychological Bulletin, 136, 1068-1091. doi:10.1037/a0021232

Charles, S. T., \& Carstensen, L. L. (2008). Unpleasant situations elicit different emotional responses in younger and older adults. Psychology and Aging, 23, 495-504. doi:10.1037/a0013284

Charles, S. T., \& Carstensen, L. L. (2010). Social and emotional aging. Annual Review of Psychology, 61, 383-409. doi:10.1146/annurev.psych .093008 .100448

Craik, F. I. M. (1999). Memory, aging, and survey measurement. In N. Schwarz, D. Park, B. Knäuper \& S. Sudman (Eds.), Cognition, aging, and self-reports (pp. 95-115). Philadelphia, PA: Psychology Press.

Denver, J. W., Reed, S. F., \& Porges, S. W. (2007). Methodological issues in the quantification of respiratory sinus arrhythmia. Biological Psychology, 74, 286-294. doi:10.1016/j.biopsycho.2005.09.005

Diamond, L. M., \& Otter-Henderson, K. D. (2007). Physiological measures. In R. W. Robins, C. Fraley, \& R. F. Krueger (Eds.), Handbook of research methods in personality psychology (pp. 370-388). New York, NY: Guilford Press.

Fahrenberg, J., Foerster, F., Smeja, M., \& Mueller, W. (1997). Assessment of posture and motion by multichannel piezoresistive accelerometer recordings. Psychophysiology, 34, 607-612. doi:10.1111/j.14698986.1997.tb01747.x

Ferrari, A. U., Radaelli, A., \& Centola, M. (2003). Aging and the cardiovascular system. Journal of Applied Physiology, 95, 2591-2597.

Ferrer-Caja, E., Crawford, J. R., \& Bryan, J. (2002). A structural modeling examination of the executive decline hypothesis of cognitive aging through reanalysis of Crawford et al.'s (2000) data. Aging, Neuropsychology, and Cognition, 9, 231-249. doi:10.1076/anec.9.3.231.9611

Fitzsimons, G. M., \& Bargh, J. A. (2004). Automatic self-regulation. In K. D. Vohs \& R. F. Baumeister (Eds.), Handbook of self-regulation: Research, theory, and applications (pp. 151-170). New York, NY: Guilford Press.
Folkow, B., \& Svanborg, A. (1993). Physiology of cardiovascular aging. Physiological Reviews, 73, 725-764.

Goedhart, A. D., Van Der Sluis, S., Houtveen, J. H., Willemsen, G., \& De Geus, E. J. C. (2007). Comparison of time and frequency domain measures of RSA in ambulatory recordings. Psychophysiology, 44, 203 215. doi:10.1111/j.1469-8986.2006.00490.x

Graham, J. E., Christian, L. M., \& Kiecolt-Glaser, J. K. (2006). Stress, age, and immune function: Toward a lifespan approach. Journal of Behavioral Medicine, 29, 389-400. doi:10.1007/s10865-006-9057-4

Gross, J. J., Carstensen, L. L., Pasupathi, M., Tsai, J., Götestam Skorpen, C., \& Hsu, A. Y. C. (1997). Emotion and aging: Experience, expression, and control. Psychology and Aging, 12, 590-599. doi:10.1037/08827974.12.4.590

Gross, J. J., \& Thompson, R. A. (2007). Emotion regulation: Conceptual foundations. In J. J. Gross (Ed.), Handbook of emotion regulation (pp. 3-24). New York, NY: Guilford Press.

Grossman, P., \& Taylor, E. W. (2007). Toward understanding respiratory sinus arrhythmia: Relations to cardiac vagal tone, evolution and biobehavioral functions. Biological Psychology, 74, 263-285. doi:10.1016/ j.biopsycho.2005.11.014

Heckhausen, J., Wrosch, C., \& Schulz, R. (2010). A motivational theory of life-span development. Psychological Review, 117, 32-60. doi:10.1037/ a0017668

Hoffman, L., \& Stawski, R. S. (2009). Persons as contexts: Evaluating between-person and within-person effects in longitudinal analysis. Research in Human Development, 6, 97-120. doi:10.1080/ 15427600902911189

Holmes, T. H., \& Rahe, R. H. (1967). The Social Readjustment Rating Scale. Journal of Psychosomatic Research, 11, 213-218. doi:10.1016/ 0022-3999(67)90010-4

Huppelsberg, J., \& Walter, K. (2005). Kurzlehrbuch Physiologie [Textbook physiology]. Stuttgart, Germany: Thieme.

Isaacowitz, D. M., \& Blanchard-Fields, F. (2012). Linking process and outcome in the study of emotion and aging. Perspectives on Psychological Science, 7, 3-17. doi:10.1177/1745691611424750

Isaacowitz, D. M., Toner, K., Goren, D., \& Wilson, H. R. (2008). Looking while unhappy: Mood congruent gaze in young adults, positive gaze in older adults. Psychological Science, 18, 843-853. doi:10.1111/j.14679280.2008.02167.x

Keil, A., \& Freund, A. M. (2009). Changes in the sensitivity to appetitive and aversive arousal across adulthood. Psychology and Aging, 24, 668680. doi:10.1037/a0016969

Kliegl, R., Smith, J., \& Baltes, P. B. (1989). Testing-the-limits and the study of adult age differences in cognitive plasticity of a mnemonic skill Developmental Psychology, 25, 247-256. doi:10.1037/00121649.25.2.247

Kreibig, S. D. (2010). Autonomic nervous system activity in emotion: A review. Biological Psychology, 84, 394-421. doi:10.1016/j.biopsycho 2010.03.010

Kunzmann, U., \& Richter, D. (2009). Emotional reactivity across the adult life span: The cognitive pragmatics make a difference. Psychology and Aging, 24, 879-889. doi:10.1037/a0017347

Labouvie-Vief, G. (2003). Dynamic integration: Affect, cognition, and the self in adulthood. Current Directions in Psychological Science, 12 201-206. doi:10.1046/j.0963-7214.2003.01262.x

Labouvie-Vief, G. (2008). Dynamic integration theory: Emotion, cognition, and equilibrium in later life. In V. Bengtson, M. Silverstein, N. Putney, \& D. Gans (Eds.), Handbook of theories of aging (pp. 277-293). New York, NY: Springer.

Labouvie-Vief, G., Jain, E., Diehl, M., \& Fang, Z. (2007). Six-year change in affect optimization and affect complexity across the adult life span: A further examination. Psychology and Aging, 22, 738-751. doi:10.1037/ 0882-7974.22.4.738

Larcom, M. J., \& Isaacowitz, D. M. (2009). Rapid emotion regulation after 
mood induction: Age and individual differences. The Journals of Gerontology: Series B: Psychological Sciences and Social Sciences, 64(B), 733-741. doi:10.1093/geronb/gbp077

Lawton, M. P. (2001). Emotion in later life. Current Directions in Psychological Science, 10, 120-123. doi:10.1111/1467-8721.00130

Lawton, M. P., Kleban, M. H., Rajagopal, D., \& Dean, J. (1992). Dimensions of affective experience in three age groups. Psychology and Aging, 7, 171-184. doi:10.1037/0882-7974.7.2.171

Lazarus, R. S. (1999). Stress and emotion: A new synthesis. New York, NY: Springer.

Lazarus, R. S. (2000). Toward better research on stress and coping. American Psychologist, 55, 665-673. doi:10.1037/0003-066X.55.6.665

Lazarus, R. S., \& Folkman, S. (1984). Stress, appraisal, and coping. New York, NY: Springer

Levenson, R. W. (2000). Expressive, physiological, and subjective changes in emotion across adulthood. In S. H. Qualls \& N. Abeles (Eds.), Psychology and the aging revolution: How we adapt to longer life (pp. 123-140). doi:10.1037/10363-007

Levine, L. J., \& Bluck, S. (1997). Experienced and remembered emotional intensity in older adults. Psychology and Aging, 12, 514-523. doi: 10.1037/0882-7974.12.3.514

Lindenberger, U., \& Baltes, P. B. (1995). Testing-the-limits and experimental simulation: Two methods to explicate the role of learning in development. Human Development, 38, 349-360. doi:10.1159/ 000278341

Lindenberger, U., von Oertzen, T., Ghisletta, P., \& Hertzog, C. (2011). Cross-sectional age variance extraction: What's change got to do with it? Psychology and Aging, 26, 34-47. doi:10.1037/a0020525

Malik, M., Camm, A. J., Bigger, J. T., Jr., Breithardt, G., Cerutti, S., Cohen, R. J., . . Singer, D. H. (1996). Heart rate variability: Standards of measurement, physiological interpretation, and clinical use. European Heart Journal, 17, 354-381.

Mathie, M. J., Coster, A. C. F., Lovell, N. H., \& Celler, B. G. (2004). Accelerometry: Providing an integrated, practical method for long-term, ambulatory monitoring of human movement. Physiological Measurement, 25, 1-20. doi:10.1088/0967-3334/25/2/R01

Minkel, J. D., Banks, S., Htaik, O., Moreta, M. C., Jones, C. W., McGlinchey, E. L., ... Dinges, D. F. (2012). Sleep deprivation and stressors: Evidence for elevated negative affect in response to mild stressors when sleep deprived. Emotion. Advance online publication. doi:10.1037/a0026871

Mroczek, D. K., \& Almeida, D. M. (2004). The effect of daily stress, personality, and age on daily negative affect. Journal of Personality, 72, 355-378. doi:10.1111/j.0022-3506.2004.00265.x

Muthén, L. K., \& Muthén, B. O. (2008). Mplus (Version 5) [Computer software]. Los Angeles, CA: Muthén \& Muthén.

Neupert, S. D., Almeida, D. M., \& Charles, S. T. (2007). Age differences in reactivity to daily stressors: The role of personal control. The Journals of Gerontology: Series B: Psychological Sciences and Social Sciences, 62(B), 216-225. doi:10.1093/geronb/62.4.P216

Ochsner, K. N., \& Gross, J. J. (2004). Thinking makes it so: A social cognitive neuroscience approach to emotion regulation. In K. D. Vohs \& R. F. Baumeister (Eds.), Handbook of self-regulation: Research, theory, and applications (pp. 229-255). New York, NY: Guilford Press.

Porges, S. W., Doussard-Roosevelt, J. A., \& Maiti, A. (1994). Vagal tone and the physiological regulation of emotion. Monographs of the Society for Research in Child Development, 59, 167-186. doi:10.2307/1166144

Pugh, K. G., \& Wei, J. Y. (2001). Clinical implications of physiological changes in the aging heart. Drugs and Aging, 18, 263-276. doi:1170229X/01/0004-0263

Raudenbush, S., Bryk, A., \& Congdon, R. (2004). HLM 5: Hierarchical linear and nonlinear modeling (Version 5.64) [Computer software]. Lincolnwood, IL: Scientific Software International.

Richards, J. M., \& Gross, J. J. (1999). Composure at any cost? The cognitive consequences of emotion suppression. Personality and Social Psychology Bulletin, 25, 1033-1044. doi:10.1177/01461672992511010

Riediger, M., Schmiedek, F., Wagner, G. G., \& Lindenberger, U. (2009). Seeking pleasure and seeking pain: Differences in pro- and contrahedonic motivation from adolescence to old age. Psychological Science, 20, 1529-1535. doi:10.1111/j.1467-9280.2009.02473.x

Russell, J. A. (1980). A circumplex model of affect. Journal of Personality and Social Psychology, 39, 1161-1178. doi:10.1037/h0077714

Scheibe, S., \& Blanchard-Fields, F. (2010). Emotional aging: Recent findings and future trends. The Journals of Gerontology: Series B: Psychological Sciences and Social Sciences, 65(B), 135-144. doi: 10.1093/geronb/gbp132

Sliwinski, M. J., Almeida, D. M., Smyth, J., \& Stawski, R. S. (2009). Intraindividual change and variability in daily stress processes: Findings from two measurement-burst diary studies. Psychology and Aging, 24, 828-840. doi: $10.1037 / \mathrm{a} 0017925$

Stawski, R. S., Almeida, D. M., Sliwinski, M. J., \& Smyth, J. M. (2008) Reported exposure and emotional reactivity to daily stressors: The roles of adult age and global perceived stress. Psychology and Aging, 23, 52-61. doi:10.1037/0882-7974.23.1.52

Steptoe, A., Moses, J., \& Edwards, S. (1990). Age-related differences in cardiovascular reactions to mental stress tests in women. Health Psychology, 9, 18-34. doi:10.1037/0278-6133.9.1.18

Uchino, B. N., Birmingham, W., \& Berg, C. A. (2010). Are older adults less or more physiologically reactive? A meta-analysis of age-related differences in cardiovascular reactivity to laboratory tasks. The Journals of Gerontology: Series B: Psychological Sciences and Social Sciences, 65(B), 154-162. doi:10.1093/geronb/gbp127

Uchino, B. N., Holt-Lunstad, J., Bloor, L. E., \& Campo, R. A. (2005). Aging and cardiovascular reactivity to stress: Longitudinal evidence for changes in stress reactivity. Psychology and Aging, 20, 134-143. doi: 10.1037/0882-7974.20.1.134

Uchino, B. N., Uno, D., Holt-Lunstad, J., \& Flinders, J. B. (1999). Agerelated differences in cardiovascular reactivity during acute psychological stress in men and women. The Journals of Gerontology: Series B: Psychological Sciences and Social Sciences, 54(B), 339-346. doi: 10.1093/geronb/54B.6.P339

Umetani, K., Singer, D. H., McCraty, R., \& Atkinson, M. (1998). Twentyfour hour time domain heart rate variability and heart rate: Relations to age and gender over nine decades. Journal of the American College of Cardiology, 31, 593-601. doi:10.1016/S0735-1097(97)00554-8

Verhaeghen, P., \& Salthouse, T. A. (1997). Meta-analyses of age-cognition relations in adulthood: Estimates of linear and nonlinear age effects and structural models. Psychological Bulletin, 122, 231-249. doi:10.1037/ 0033-2909.122.3.231

Walker, M. P., \& van der Helm, E. (2009). Overnight therapy? The role of sleep in emotional brain processing. Psychological Bulletin, 135, 731748. doi: $10.1037 / \mathrm{a} 0016570$

Watson, D., \& Tellegen, A. (1985). Toward a consensual structure of mood. Psychological Bulletin, 98, 219-235. doi:10.1037/00332909.98.2.219

Williams, L. E., Bargh, J. A., Nocera, C. C., \& Gray, J. R. (2009). The unconscious regulation of emotion: Nonconscious reappraisal goals modulate emotional reactivity. Emotion, 9, 847-854. doi:10.1037/ a0017745

Wood, R., Maraj, B., Lee, C. M., \& Reyes, R. (2002). Short-term heart rate variability during a cognitive challenge in young and older adults. Age and Ageing, 31, 131-135. doi:10.1093/ageing/31.2.131

Wrzus, C., Denissen, J. J. A., \& Lüdtke, O. (2012). Standardized coefficients in multilevel modeling. Manuscript submitted for publication.

Received February 24, 2011

Revision received March 5, 2012 Accepted March 16, 2012 